\title{
Rearview
}

\section{Apple in a strategic bind}

\section{A regular column on the information industries}

\section{Peter Curwen}

Peter Curwen is Visiting Professor at the Newcastle Business School, Northumbria University, Newcastle upon Tyne, UK.
There are, predictably, variations among consultancies that collect data on the smartphone market as to its status at the end of 2015 and its prospects for 2016. However, absolute precision is not necessary to determine the major changes that are taking place.

It is useful to begin with the International Data Corporation (IDC) worldwide quarterly mobile phone tracker. During 2013, this revealed that Android was the operating system (OS) in 802 million smartphone shipments (78.7 per cent of the total), whereas Apple's iOS accounted for 153 million (15.1 per cent). Hence, they accounted between them for 93.8 per cent of total shipments. In 2014, the figures were 1,059 million (81.5 per cent) for Android and 193 million (14.8 per cent) for iOS. Hence, they accounted for 96.3 per cent of total shipments. It can be concluded from this that, despite the best efforts of Microsoft, there is very little room left in the market for any other OS.

On the face of it, having a strong duopoly would appear to be excellent news for the two parties involved. However, there is, as ever, one major fly in the ointment. Market share is not all that important when a market is growing rapidly, as even a static share represents a significant increase in shipments. But if market growth slows, then even duopolists may be forced to compete harder to maintain market share and avoid a reduction in shipments.

To which may be added a second crucial feature of the smartphone market, that iOS is exclusive to Apple, whereas Android is used by virtually all other smartphone vendors. According to IDC, total smartphone market shipments rose by 9.8 per cent during 2015 to 1,433 million - a figure very similar to that cited by rival Strategy Analytics. iOS accounted for 232 million - a 20 per cent increase in 2014 - and hence its market share rose to 16.2 per cent, whereas the leading Android vendor, Samsung, accounted for 325 million, only just ahead of its total shipments in 2014. On the face of it, a resounding victory for Apple, especially given the average selling price of an iPhone, was recorded as \$691.

However, there was one other market feature of some significance. Given Samsung's static shipments, it was evident that the vendors responsible for the growth of Android were much smaller, including Huawei, the little-known Chinese vendors Xiaomi, Oppo and 
Vivo (which currently sell almost entirely in China) and Korea's LG. Ironically, Lenovo, which had acquired Motorola, saw its market share fall. Furthermore, in the market with arguably the greatest potential for future growth, India, the market leader was the even less-well-known locally based Micromax Informatics.

Hence, the question arises as to whether or not Apple is well-placed to see out 2016 on a high. It is helpful to begin by examining the Apple share price, as it is a good indicator of market sentiment. Three years prior to the time of writing end-April 2013 - this bottomed out at $\$ 55.8$, having fallen from $\$ 100$ in September 2012. By the end of May 2015 , it had reached a new peak of $\$ 132.5$ - not surprisingly given the shipment data cited above - but 11 months later, it stands at $\$ 96$ down over 25 per cent despite the seemingly positive data for end-2015. The key issue is that Apple normally derives roughly 60 per cent of its revenue from iPhone sales, and it is precisely this part of the overall business that is in a strategic bind.

After a boom period during which customers swapped their feature phones for smartphones in huge numbers, the high-end smartphone market is saturated and it has become increasingly difficult to find new "must have" features that will kick-start the next upgrade cycle. There is still growth potential at the cheaper end of the market but that is hardly Apple's natural preserve as it provides volume without much, if any, profit. Furthermore, it may not even work as a strategy - for example, it was going downmarket that largely led to the takeover of Motorola.

The potential strategic saviour in 2016 - building in features previously only found at the high end - is widely agreed to be a noticeable improvement in the functionality of lower-end models. However, this must be done in such a way as to not induce owners of high-end models to trade down in the belief that they can get the same functionality at a cheaper price. One obvious trick is to reduce the screen size - hence, the introduction of the iPhone SE as effectively a smaller-screen version of the iPhone $6 \mathrm{~S}$ at a much lower price. For its part, Samsung will shortly launch the Galaxy C which, at roughly $\$ 300$, is expected to compete successfully with similarly priced rival models while simultaneously proving unattractive to potential buyers of its high-end S7.

LG appears to have chosen the same strategy but, as noted above, the likes of Huawei in China and Micromax in India, the two largest markets, and locally based vendors in general, are determined to keep out the incursion of Apple which must rely upon the iPhone SE and price it competitively - that is to say, with a lower profit margin than it is accustomed to in the more advanced markets of Europe and the USA. The introduction of the Apple Watch and the very limited improvements expected in the forthcoming iPhone 7 cannot offset Apple's competitive disadvantage in markets where lower specifications and, hence, cheaper handsets dominate the market.

Apple has just reported its results for the first three months of 2016 (technically its second quarter), and these revealed the first-ever year-on-year decline in iPhone sales, down by a significant 16 per cent, with the average unit price falling to $\$ 642$. The fall was attributed to a generally poor economic environment and, in particular, to difficulties in Hong Kong and mainland China. This was hardly good news given the importance of the Asia-Pacific region for Apple's prospects for 2016 as a whole. While the overall smartphone market may indeed pick up once the USA Presidential election is finally resolved, although the 2016 Q1 figures show no growth compared to 2015 Q1 and possibly a decline, this may merely reveal that Apple can no longer rely upon the mantra "make it and they will come" and, crucially, upgrade regularly. On the other hand, the ever-growing base of iPhone owners means that the Services division, which includes the App store, Apple Pay, Apple Music and the iCloud, is proving to be more resilient and this is a company that, when all is said and done, generates billions of dollars of cash flow each quarter. Hence, there is no need for Apple (and its shareholders) to panic - at least, not until the prospects for the iPhone SE become clearer - but the one certain thing is that Apple cannot simply continue to rely upon the strategy that has underpinned its massive success over the past decade.

\section{About the author}

Peter Curwen is Visiting Professor of Mobile Communications at the Newcastle Business School. Peter Curwen can be contacted at: pjcurwen@hotmail.com 